\title{
Effects of gamma and electron beam irradiations on the triacylglycerol profile of fresh and stored Castanea sativa Miller samples
}

\author{
João C.M. Barreira ${ }^{\mathrm{a}, \mathrm{b}}$, Márcio Carocho ${ }^{\mathrm{a}}$, Isabel C.F.R. Ferreira ${ }^{\mathrm{a},{ }^{*},}$ Amilcar L. \\ Antonio $^{\mathrm{a}, \mathrm{c}, \mathrm{d}}$, Iwona Kaluska ${ }^{\mathrm{e}}$, M. Luisa Botelho ${ }^{\mathrm{c}}$, Albino Bento ${ }^{\mathrm{a}}$, \\ M. Beatriz P.P. Oliveira ${ }^{b}$
}

${ }^{a}$ CIMO/Escola Superior Agrária, Instituto Politécnico de Bragança, Apartado 1172, 5301-855 Bragança, Portugal.

${ }^{\mathrm{b}}$ REQUIMTE, Departamento de Ciências Químicas, Faculdade de Farmácia da Universidade do Porto, Rua Jorge Viterbo Ferreira, 228, 4050-313 Porto, Portugal.

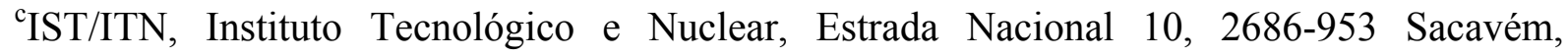
Portugal.

${ }^{\mathrm{d} D e p a r t a m e n t o ~ d e ~ F i ́ s i c a ~ F u n d a m e n t a l, ~ U n i v e r s i d a d e ~ d e ~ S a l a m a n c a, ~ P l a z a ~ d e ~ l a ~ M e r c e d, ~}$ 37008 Salamanca, Spain.

${ }^{\mathrm{e}}$ Centre for Rad. Research and Techn., Inst. of Nuclear Chem. and Technology, Dorodna str.16, 03-195 Warsaw, Poland.

*Corresponding author: I.C.F.R. Ferreira: iferreira@ipb.pt, tel. +351-273303219, fax +351273325405). 


\begin{abstract}
The present chestnut (Castanea sativa Miller) commercialization dynamics, including distribution to novel markets, demands suitable conservation technologies. Irradiation has been considered a promising alternative to chemical fumigation (legally forbidden and harmful for human health and environment) or heat treatments (technological difficulties and low efficiency). Following previous studies on the effects of irradiation in different chemical parameters, the present work aims to perform an evaluation of the effects of electron beam and $\gamma$-irradiation on the triacylglycerol profiles of fresh and stored chestnuts. An analysis of variance with type III sums of squares was performed using the general linear model procedure. As classification technique, a linear discriminant analysis using the stepwise procedure was also applied. Independently of irradiation type, samples irradiated with higher doses showed higher modifications in triacylglycerol profiles. In fact, samples irradiated with 1 and 3 kGy were clearly separated from the remaining groups in the linear discriminant analysis. The obtained results highlight the potential of triacylglycerol profiles as indicators of chestnuts irradiation. However, irradiation might be recommended as a suitable method for chestnuts preservation.
\end{abstract}

Keywords: Chestnut; electron beam irradiation; gamma irradiation; triacylglycerols; linear discriminant analysis. 


\section{Introduction}

Chestnut quality is measured by external factors such as color, shape, size, surface blemish and mold, which are very important for consumers' acceptance. Internal disorders may result from anatomical or physiological changes like moisture loss, chemical conversion, discoloration, senescence, microorganism attack, cell breakdown (physiological decay) and insect injury (Upchurch et al., 1993). Weight losses due to dehydration and development of insects and microorganisms are the two main problems of chestnuts preservation, and neither chemical fumigants, nor heat treatment, represent an effective solution (Pinto et al., 2007). Furthermore, chemical fumigation is harmful to the human health and to the environment (UNEP, 2006), while heat treatments do not prevent mold growth (Jermini et al., 2006). Quality requirements demand enhanced conservation techniques for chestnuts and related products. In this context, decontamination methods based on high-energy electrons or $\gamma$-rays irradiation are being studied as alternatives; Arici et al. (2007) irradiated black cumin with 2.5 to $10 \mathrm{kGy}$ for the purpose of microorganism's elimination, while studying the effects on physico-chemical properties and on fatty acids profile. Irradiation beneficial effects include reduction of storage losses, shelf life extension, and improvement of microbiological and parasitological safety of foods, while being safe to the environment. Hence, irradiation might be considered a promising conservation technology, bearing in mind that the doses applied on fresh fruits and processed fruit products are limited by the impact on their quality (Arvanitoyannis et al., 2009). Particularly, gamma-irradiation was already applied to diverse food products such as tuber and bulb crops, stored grains, dried ingredients, meats, poultry and fish, or fruits (Farkas, 2006). It can also be applied to chestnuts which contain only 1\% of fat, overcoming the production of off-odor compounds due to the radiation-induced breakdown of lipids common in high-fat-containing foods (Niyas et al. 2003). 
Electron beam irradiation is also widely applied to improve food quality and safety. The use of electron accelerators as source of radiation has technological advantages like higher throughput, wider flexibility and more potential to overcome public objections to radioactive isotopic sources (Supriya et al., 2012). Nevertheless, the irradiation efficacy is highly dependent on intrinsic factors of each food product, requiring continuous studies of exposure time (doses) and geometry (dose uniformity) (Belchior et al., 2007; Kim et al., 2007). The effects of radiation on chestnuts composition have been progressively studied, either using electron beam treatment (Carocho et al., 2012) or $\gamma$-irradiation (Antonio et al., 2012a). Yet, the effects of these irradiations in chestnut triacylglycerol (TAG) profiles have not been evaluated. TAG profile is specific of each natural product and has been used for studying crystallization phenomena, detecting adulteration of specialty fats and oils, and recognition of oils origin, being one of the prime determinants in the study of oils oxidation (Zeb, 2012).

The evaporative light-scattering detector (ELSD) is a suitable solution for TAG analysis, since it is a mass-sensitive detector that responds to any analyte less volatile than the mobile phase. Furthermore, ELSD has a low background signal, a non-specific response (unlike a flame ionization detector), compatibility with gradient elution (dissimilarly to the refraction index detector) and with a broad range of solvents, besides having a signal independent of the degree of saturation and chain length (unlike an ultraviolet detector) (Rombaut et al., 2009). Hence, this parameter might be a good indicator of the effects of irradiation on natural food matrixes. Herein, the main purpose was evaluating alterations in the TAG profiles of chestnuts submitted to electron beam or $\gamma$-irradiation $(0,0.5,1$ and $3 \mathrm{kGy})$, analyzed immediately after irradiation or after 30 days storage, assessing its potential use as an irradiation marker. Furthermore, obtained data constitute complementary information to previous results regarding irradiation effects on the chemical composition and bioactivity of chestnuts (Antonio et al., 2012a,b; Carocho et al., 2012; Fernandes et al., 2011a,b). 


\section{Materials and methods}

\subsection{Standards and reagents}

Triacylglycerols 1,2,3-tripalmitoylglycerol (PPP), 1,2,3-tristearoylglycerol (SSS), 1,2,3trilinolenoylglycerol ( $\mathrm{LnLnLn}$ ), and 1,2,3-tripalmitoleoylglycerol (PoPoPo), of purity $>98 \%$, and 1,2,3-trioleoylglycerol (OOO), 1,2,3-trilinoleoylglycerol (LLL), 1,2-dilinoleoyl-3palmitoyl-rac-glycerol (PLL), 1,2-dilinoleoyl-3-oleoyl-rac-glycerol (OLL), 1,2 -dipalmitoyl3-oleoyl-rac-glycerol (PPO), 1,2-dioleoyl-3-stearoyl-rac-glycerol (OOS), 1-palmitoyl-2oleoyl-3-linoleoylglycerol (POL), and 1,2-dioleoyl-3-palmitoyl-rac-glycerol (POO), of $\approx 99 \%$ purity, were purchased from Sigma (St. Louis, MO, USA). Petroleum ether was of analytical grade and obtained from Fisher Scientific (Leicestershire, UK). Acetonitrile and acetone were of HPLC grade and obtained from Merck (Darmstadt, Germany). The code letters used for the fatty acids are: Po, palmitoleic; L, linoleic; Ln, linolenic; M, myristic; O, oleic; P, palmitic; S, stearic.

\subsection{Samples}

The used chestnut samples, previously studied for their nutritional value (Carocho et al., 2012; Fernandes et al., 2011b), were obtained in Bragança, Trás-os-Montes (Portugal). All the samples belong to Longal cultivar from Protected Designation of Origin (PDO) "Castanha da Terra Fria". This PDO was created in 1994, with the normative decree 44/94 from February $3^{\text {rd }}$, where it is defined as the fruit obtained from Castanea sativa, including the varieties Longal, Judia, Amarelal, Lamela, Aveleira, Boaventura, Trigueira, Martainha and Negral (Portuguese Government Legislation, 1994: Decreto Normativo 44/94). For each irradiation procedure, chestnuts were divided in four groups: control (non-irradiated, $0 \mathrm{kGy}$ ), sample 1 (0.5 kGy), sample 2 (1 kGy), and sample 3 (3 kGy) with fifteen units per group. An 
independently control was used for each irradiation procedure (gamma irradiation was performed in Portugal, while electron beam irradiation was conducted in Poland), in order to guarantee the same conditions for all the samples avoiding a biased effect that might have been induced by potential differences among the two control samples.

\subsection{Samples irradiation}

Electron beam radiation. The irradiation with electrons was performed at the INCT Institute of Nuclear Chemistry and Technology - in Warsaw, Poland, with an e-beam of 10 $\mathrm{MeV}$ of energy. Pulse duration $5.5 \mu$ s, pulse frequency $440 \mathrm{~Hz}$, average beam current $1.1 \mathrm{~mA}$, scan width of $68 \mathrm{~cm}$, conveyer speed in the range $20-100 \mathrm{~cm} / \mathrm{min}$, scan frequency $5 \mathrm{~Hz}$. The absorbed dose was $0.53,0.83$ and $2.91 \mathrm{kGy}$, with an uncertainty of $20 \%$ for two first doses and $15 \%$ for the last dose. To estimate the dose, Amber Perspex and Gammachrome YR dosimeters (from Harwell Company, U.K.) and a Graphite Calorimeter were used, depending on the dose level. The electrical resistance was read for the calorimeter dosimeter and converted in dose according to a previous calibrated curve.

Gamma radiation. The irradiation of the samples was performed in a Co- 60 experimental chamber with four sources, a total activity of $267 \mathrm{TBq}(6.35 \mathrm{kCi})$ in November 2011 (Precisa 22, Graviner Manufacturing Company Ltd, U.K.). After irradiation geometry dose rate estimation, using the Fricke dosimeter and the procedure described in the standards (ASTM, 1992), each group of fruit samples for irradiation was placed in a PMMA (polymethyl methacrylate) box to be irradiated at the predicted dose, at ambient atmosphere and temperature $\left(15^{\circ} \mathrm{C}\right)$. During the irradiation process, 4 routine dosimeters were used for each group for the higher dose to monitor the process (Amber Perspex dosimeters, from Harwell Company, U.K.). The samples were rotated up-side down $\left(180^{\circ}\right)$ at half of the time, to increase the dose uniformity. The Amber Perspex dosimeters were read in a UV-VIS 
Spectrophotomer (Shimadzu mini UV 1240 spectrophotometer) at $603 \mathrm{~nm}$, two readings for each, to estimate the dose according to a previous calibration curve. The estimated doses after irradiation were $0.6 \pm 0.1 \mathrm{kGy}, 1.1 \pm 0.1 \mathrm{kGy}$ and $3 \pm 0.3 \mathrm{kGy}$ for each of the mentioned groups, respectively, at a dose rate of $0.8 \pm 0.1 \mathrm{kGy} \mathrm{h}^{-1}$.

For simplicity, from now on, in the tables and graphs we considered the values $0,0.5,1$ and $3 \mathrm{kGy}$, for non-irradiated and irradiated samples.

\subsection{Triacylglycerols analysis}

Before the extraction procedure, each sample was manually peeled (inner and outer skins), milled to obtain a dried powder (20 mesh) and lyophilized (Free Zone 4.5, Labconco, Kansas, MO). Each sample (50 g), was then submitted to an extraction with petroleum ether $\left(40-60{ }^{\circ} \mathrm{C}\right)$ performed in Soxhlet apparatus for $1.5 \mathrm{~h}$. The chromatographic analyses were carried out according to the procedure previously described (Barreira et al., 2009), with a Jasco (Tokyo, Japan) HPLC system, equipped with a PU-1580 quaternary pump and a Jasco AS-950 automatic sampler with a $10 \mu \mathrm{L}$ loop. Detection was performed with an evaporative light-scattering detector (ELSD) (model 75-Sedere, Alfortville, France). The chromatographic separation of the compounds was achieved with a Kromasil $100 \mathrm{C}_{18}(5 \mu \mathrm{m} ; 250 \times 4.6 \mathrm{~mm})$ column (Teknokroma, Barcelona, Spain) operating at room temperature $\left(\approx 20^{\circ} \mathrm{C}\right)$. The mobile phase was a mixture of acetone and acetonitrile (70:30), in an isocratic mode, at an elution rate of $1 \mathrm{~mL} / \mathrm{min}$. Detection was performed with an evaporative light-scattering detector (ELSD) (model 75-Sedere, Alfortville, France) with the following settings: evaporator temperature $40{ }^{\circ} \mathrm{C}$, air pressure 3.5 bar and photomultiplier sensitivity 6 . Taking into account the selectivities ( $R$, relative retention times to LLL), peaks were identified according to the logarithms of $\mathrm{R}$ in relation to homogeneous TAG standards. Quantification of the peaks was made by internal normalization of chromatographic peak area, and the results were expressed 
in relative percentage, assuming that the detector response was the same for all the compounds within each analysis. Data were analyzed using the Borwin-PDA Controller Software (JMBS, France).

\subsection{Statistical analysis}

Four levels $(0,0.5,1.0$ and $3.0 \mathrm{kGy})$ of irradiation were assayed in each case (electron beam and $\gamma$-irradiation), considering samples stored for 30 days $\left(4^{\circ} \mathrm{C}\right.$, with a relative humidity close to $92 \%$ ) or immediately analysed in comply with the EN8417 guideline. In each sample, two extractions were performed, and each extract was injected twice in the HPLC system. Data was expressed as means \pm standard deviations. All statistical tests were performed at a 5\% significance level using the SPSS software, version 18.0.

An analysis of variance (ANOVA) with type III sums of squares was performed using the GLM (General Linear Model) procedure of the SPSS software. The dependent variables were analyzed using 2-way ANOVA, with the factors "electron beam irradiation dose" (EBD) or " $\gamma$-irradiation dose" (GID) and "storage time" (ST). The effects of each type of irradiation were evaluated individually, considering stored and non-stored samples. The interaction of both factors, storage time (ST), and irradiation (EBD or GID) was also tested. When a statistically significant interaction $(\mathrm{EBD} \times \mathrm{ST}$ or $\mathrm{GID} \times \mathrm{ST})$ was detected, the two factors were evaluated simultaneously by the estimated marginal means plots for all levels of each single factor. Alternatively, if no statistical significant interaction was verified, means were compared using Tukey's honestly significant difference (HSD) multiple comparison test.

In addition, a linear discriminant analysis (LDA) was used to assess the influence of different irradiation doses on TAG profile. Two different sets of data were constructed: the first with varying doses of $\gamma$-irradiation and different storage times; the second with varying doses of electron beam irradiation and different storage times. A stepwise technique, using the 
Wilks' $\lambda$ method with the usual probabilities of $F$ (3.84 to enter and 2.71 to remove), was applied for variable selection. This procedure uses a combination of forward selection and backward elimination procedures, where before selecting a new variable to be included, it is verified whether all variables previously selected remain significant (Bosque-Sendra et al., 2012). With this approach, it is possible to identify the significant variables obtained for each sample. To verify which canonical discriminant functions were significant, the Wilks' $\lambda$ test was applied. A leaving-one-out cross-validation procedure was carried out to assess the model performance.

\section{Results and discussion}

In food irradiation, the minimum absorbed dose should guarantee consumer safety, while the maximum absorbed dose should not compromise wholesomeness, structural integrity, functional properties, or sensory attributes (EC, 2003). Chestnut physical parameters were negatively affected (softening in texture) by doses higher than $3 \mathrm{kGy}$ (Antonio et al., 2012b). Accordingly, in the present research, doses were restricted up to $3 \mathrm{kGy}$.

The mean values obtained for TAG profiles of each sample are shown in Table 1. Besides the tabled compounds, LLnLn was also detected in vestigial amounts $(<0.1 \%)$. The values are presented in relative percentage, due to the limited number of available high purity standards. Furthermore, the diversity of TAGs in each oil would make virtually impossible to construct a calibration curve for each one. The relative peak areas might be converted into relative TAG concentration, assuming linearity and uniformity of the detector signal, regardless of the TAG species and absolute concentration (Rombaut et al., 2009). Regarding elution order, and denoting $\mathrm{S}=$ saturated, $\mathrm{M}=$ monoenoic, $\mathrm{D}=$ dienoic and $\mathrm{T}=$ trienoic acids, the chromatographic separation is, in terms of retention time, defined as: $\mathrm{SSS}>\mathrm{SSM}>\mathrm{SMM}>$ 
$\mathrm{SSD}>\mathrm{MMM}>\mathrm{SMD}>\mathrm{MMD}>\mathrm{SDD}>\mathrm{SST}>\mathrm{MDD}>\mathrm{SMT}>\mathrm{MMT}>\mathrm{DDD}>\mathrm{SDT}>\mathrm{MDT}>\mathrm{DDT}>\mathrm{STT}>$ MTT $>$ DTT $>$ TTT (Fuchs et al., 2011). The tabled TAG followed this theoretical order: $\mathrm{PPO}(\mathrm{SSM})>\mathrm{POO}(\mathrm{SMM})>\mathrm{OOO}(\mathrm{MMM})>\mathrm{PLP}(\mathrm{SDS})>\mathrm{POL}(\mathrm{SMD})>\mathrm{OOL}(\mathrm{MMD})>\mathrm{PLL}(\mathrm{SDD})>$ OLL(MDD) $>$ PLLn $($ SDT $)>$ OLLn(MDT) $>\operatorname{LLL}($ DDD $)>\operatorname{LLLn}($ DDT $)>\operatorname{LLnLn}($ DTT $)$, except in the cases of PLP and LLL. The detected abundances are in agreement with previous results (Barreira et al., 2009, 2012a; Lísa et al., 2009), with OLL, PLL, OOL and POL as the major compounds, followed by LLL, OOO and POO. The differences observed in both (electron beam and $\gamma$-irradiation) controls (those without irradiation or storage) might be explained by slight different times of evaluation.

Despite the differences found for individual TAG, which had statistical significance (signalized by different letters in each column) only in the cases of LLLn (Table 1) for both irradiations and OLLn for $\gamma$-irradiation, the chromatographic outputs were similar for all samples. As an example, the HPLC-ELSD TAG profile of control (A) and samples irradiated with 3 kGy (B) used in electron beam studies can be observed in Figure 1 (the chromatograms corresponding to control and $\gamma$-irradiated samples were highly similar to those presented in Figure 1; hence, those were not shown since their inclusion would not add relevant information). The interaction effects of ST and electron beam dose (EBD) was significant $(p \leq 0.002)$ in all cases except LLLn $(p=0.365)$ and OLLn $(p=0.365)$. The individual effect of each factor was also significant in most cases. A similar result was obtained for the interaction among ST and $\gamma$-irradiation dose (GID), which was significant $(p<0.014)$ for all TAG except LLLn $(p=0.169)$ and OLLn $(p=0.079)$. In general, and despite multiple comparisons could not be performed in most cases (due to the significant interaction among factors, ST $\times$ EBD and ST $\times$ GID), neither EBD nor GID seemed to induce appreciable changes in TAG profiles. In the cases where multiple comparisons could not be performed, the plotted estimated marginal means (data not shown), did not allow the identification of 
particular differences or tendencies. Even so, in order to obtain a more realistic idea about the influence of irradiation treatments, the results were scrutinized through a linear discriminant analysis (LDA).

The application of chemometric methods is a common and effective way to classify food materials (Bosque-Sendra et al., 2012; Zhang et al., 2012). LDA, for instance, was used to exploit invisible changes of the internal characteristics of blanched sweet corn yielding satisfactory classification rate of $94.3 \%$ and performed well in firmness prediction of processed sweet corn (Shao and Li, 2010).

The analysis was performed considering the applied irradiation dose. In opposition to what could be expected from the mean values presented in Table 1, the differences in TAG profiles allowed to correctly classify $100.0 \%$ of the samples for the originally grouped cases either in EBD as in GID; regarding cross-validated cases, $100 \%$ of the samples were correctly classified for GID, while $96.9 \%$ (one sample irradiated with $0.5 \mathrm{kGy}$ was classified as nonirradiated) were correctly classified for EBD.

Regarding EBD, the three plotted functions (Figure 2A) integrated 100.0\% of the observed variance (first: $78.7 \%$; second: $16.8 \%$; third: $4.5 \%$ ). The model selected 10 of the 12 inserted TAG (OLL and OOO were rejected). The first function separated primarily $3 \mathrm{kGy}$ and $1 \mathrm{kGy}$ from $0.5 \mathrm{kGy}$ and non- irradiated samples (means of the canonical variance, MCV: $0 \mathrm{kGy}=-15.493 ; 0.5 \mathrm{kGy}=-19.529 ; 1 \mathrm{kGy}=8.300 ; 3 \mathrm{kGy}=26.723$ ) being more correlated with LLL and LLLn, while the second function was mainly responsible for separating samples submitted to $0.5 \mathrm{kGy}$ and non-irradiated samples $(\mathrm{MCV}: 0 \mathrm{kGy}=4.797 ; 0.5 \mathrm{kGy}=-$ $3.601 ; 1 \mathrm{kGy}=-1.950 ; 3 \mathrm{kGy}=0.755)$.

The effect of ST was also appreciable, since 93.8\% (two non-stored samples were classified as being stored during 30 days) of the originally grouped cases and $90.6 \%$ (three 
non-stored samples were classified as being stored during 30 days) of the cross-validated cases were correctly classified. All stored samples were correctly classified.

In the case of GID, the three plotted functions (Figure 2B) also comprised $100.0 \%$ of the observed variance (first: $96.5 \%$; second: $2.8 \%$; third: $0.7 \%$ ). The model selected 7 of the 12 inserted TAG (LLL, PLLn, OLL, OOO and POO were rejected). The first function separated primarily 3 and $1 \mathrm{kGy}$ from $0.5 \mathrm{kGy}$ and non-irradiated samples $(\mathrm{MCV}: 0 \mathrm{kGy}=0.950 ; 0.5$ $\mathrm{kGy}=6.602 ; 1 \mathrm{kGy}=-2.715 ; 3 \mathrm{kGy}=-4.837)$, while the second function separated mostly samples submitted to $0.5 \mathrm{kGy}$ and non-irradiated samples $(\mathrm{MCV}: 0 \mathrm{kGy}=-2.285 ; 0.5 \mathrm{kGy}=$ $1.458 ; 1 \mathrm{kGy}=-1.630 ; 3 \mathrm{kGy}=2.457)$.

ST had also a marked effect: $90.6 \%$ (three samples stored during 30 days were classified as non-stored) of the originally grouped cases and $84.4 \%$ (fivee samples stored during 30 days were classified as non-stored) of the cross-validated cases were correctly classified. All nonstored samples were correctly classified.

The differences found in TAG profiles might result from oxidative processes (Zeb, 2012) or chemical bonds cleavage in primary and secondary reactions during irradiation (Al-Bachir, 2004). The disruption of ester bonds between fatty acids and glycerol occurs mainly in $\alpha$ and $\beta$ positions with respect to the carbonyl groups, resulting in the respective $C_{n-1}$ and $C_{n-2}$ compounds (EN 1784, 2003). The changes in TAG profiles were mostly qualitative, which is in agreement with previous studies with similar irradiation doses, reporting that fatty acid profiles remained unaffected (Barreira et al., 2012b; Fernandes et al., 2011a,b); i.e. it was not observed a decrease in fatty acids, but a rearrangement within the glycerol molecule. These changes, however, are not likely to affect the organoleptic characteristics of chestnuts, since the fat content is usually lower than $1 \%$ (Barreira et al., 2009).

\section{Conclusions}


A significant interaction was detected among GID and ST, and also among EBD and ST. In fact, ST is always a critical condition in the assessment of chestnuts chemical quality (Cecchini et al., 2011). The significant interactions did not allow relevant conclusions in the analysis of Table 1. Hence, a linear discriminant analysis was performed in order to verify significant differences in triacylglycerol profiles among irradiated and non-irradiated samples for both types of radiation. The internal validation procedure confirmed the obtained discriminant models. In fact, and independently of irradiation type, samples irradiated with higher doses ( 1 and $3 \mathrm{kGy}$ ) were clearly individualized. The obtained discriminant functions allowed good classification performances, indicating that TAG profile might be an indicator of chestnuts irradiation. Even so, irradiation can be looked up as a relevant method of protection and prevention of infection in chestnuts, since changes observed in TAG profile are not likely to affect chestnut quality.

\section{Acknowledgements}

The authors thank ON.2/QREN/EU Project no.13198/2010 for financial support of this work, to the Foundation for Science and Technology (FCT, Portugal) and COMPETE/QREN/EU for financial support to CIMO (strategic project PEst-OE/AGR/UI0690/2011) and to REQUIMTE (PEst-C/EQB/LA0006/2011). J.C.M. Barreira and A.L. Antonio also thank to FCT, POPH-QREN and FSE for their grants (SFRH/BPD/72802/2010 and SFRH/PROTEC/67398/2010, respectively). Prof. A. Chmielewski, General Director of the Institute of Nuclear Chemistry and Technology, Warsaw, Poland, for allowing e-beam irradiations. 


\section{References}

Al-Bachir, M., 2004. Effect of gamma irradiation on fungal load, chemical and sensory characteristics of walnuts (Juglans regia L.). J. Stored Prod. Res. 40, 355-362.

Antonio, A.L., Carocho, M., Bento, A., Quintana, B., Botelho, M.L., Ferreira, I.C.F.R., 2012a. Effects of gamma radiation on the biological, physico-chemical, nutritional and antioxidant parameters of chestnuts - A review. Food Chem. Toxicol. 49, 3234-3242.

Antonio, A.L., Ramalhosa, E., Kaluska, I., Quintana, B., Trigo, M.J., Ferreira, A., Bento, A., 2012b. Influence of e-beam irradiation processing on chestnuts color and texture. In International Conference of Agricultural Engineering. Valencia.

Arici, M., Arslan Colak, F.A., Gecgel, Ü., 2007. Effect of gamma radiation on microbiological and oil properties of black cumin (Nigella sativa L.). Grasas aceites 58, 339-343.

Arvanitoyannis, I.S., Stratakos, ACh., Tsarouhas, P., 2009. Irradiation applications in vegetables and fruits: a review. Crit. Rev. Food Sci. 49, 427-462.

ASTM, American Society for Testing and Materials, 1992. Practice for Using the Fricke Reference Standard Dosimetry System, ASTM E1026, Annual Book of ASTM Standards, 12.02, Philadelphia, PA.

Barreira, J.C.M., Casal, S., Ferreira, I.C.F.R., Oliveira, M.B.P.P., Pereira, J.A., 2009. Nutritional, fatty acid and triacylglycerol profiles of Castanea sativa Mill. cultivars: a compositional and chemometric approach. J. Agr. Food Chem. 57, 2836-2842.

Barreira, J.C.M., Casal, S., Ferreira, I.C.F.R., Peres, António M., Pereira, J.A., Oliveira, M.B.P.P., 2012a. Chemical characterization of chestnut cultivars from three consecutive years: Chemometrics and contribution for authentication. Food Chem. Toxicol. 50, $2311-2317$ 
Barreira, J.C.M., Antonio, A.L., Günaydi, T., Alkan, H., Bento, A., Botelho, M.L., Ferreira, I.C.F.R., 2012b. Chemometric characterization of gamma irradiated chestnuts from Turkey. Radiat. Phys. Chem. 81, 1520-1524.

Belchior, A., Botelho, M.L., Vaz, P., 2007. Monte Carlo simulations and dosimetric studies of an irradiation facility. Nucl. Instrum. Meth. A 580, 70-72.

Bosque-Sendra J.M., Cuadros-Rodríguez, L., Ruiz-Samblás, C., de la Mata, A.P., 2012. Combining chromatography and chemometrics for the characterization and authentication of fats and oils from triacylglycerol compositional data - A review. Anal. Chim. Acta 724, 1-11.

Carocho, M., Barreira, J.C.M., Antonio, A.L., Bento, A., Kaluska, I., Ferreira, I.C.F.R., 2012. Effects of electron-beam radiation on nutritional parameters of Portuguese chestnuts (Castanea sativa Mill.). J. Agr. Food Chem. 60, 7754-7760.

Cecchini, M., Contini, M., Massantini, R., Monarca, D., Moscetti, R., 2011. Effects of controlled atmospheres and low temperature on storability of chestnuts manually and mechanically harvested. Postharvest Biol. Technol. 61, 131-136.

EC, 2003. European Commission Health and Consumer Protection Directorate-General Scientific Committee on Food, Revision of the opinion of the Scientific Committee on Food on the irradiation of food, SCF/CS/NF/IRR/24 Final Report.

EN 1784, 2003. European Norm: Foodstuffs - Detection of irradiated food containing fat Gas chromatographic analysis of hydrocarbons. Available from: $<$ http://ec.europa.eu/food/food/biosafety/irradiation/1784-1996_en.pdf>

Farkas, J., 2006. Irradiation for better foods. Trends Food Sci. Tech., 17, 148-152.

Fernandes, A., Antonio, A.L., Barros, L., Barreira, J.C.M., Bento, A., Botelho, M.L., Ferreira, I.C.F.R., 2011a. Low dose $\gamma$-irradiation as a suitable solution for chestnut (Castanea 
sativa Miller) conservation: effects on sugars, fatty acids and tocopherols. J. Agr. Food Chem. 59, 10028-10033.

Fernandes, A., Barreira, J.C.M., Antonio, A.L., Bento, A., Botelho, M.L., Ferreira, I.C.F.R., 2011b. Assessing the effects of gamma irradiation and storage time in energetic value and in major individual nutrients of chestnuts. Food Chem. Toxicol. 49, 2429-2432.

Fuchs, B., Rosmarie, Sü $\beta$ R., Teuber, K., Eibisch, M., Schiller J., 2011. Lipid analysis by thin-layer chromatography - a review of the current state. J. Chromatogr. A 1218, 27542774.

Jermini, M., Conedera, M., Sieber, T.N., Sassella, A., Schärer, H., Jelmini, G., Höhn, E., 2006. Influence of fruit treatments on perishability during cold storage of sweet chestnuts. J. Sci. Food Agr. 86, 877-885.

Kim, J., Moreira, R., Huang, Y., Castell-Perez, M., 2007. 3-D dose distributions for optimum radiation treatment planning of complex foods. J. Food Eng. 79, 312-321.

Lísa, M., Holčapek, M., Boháč, M., 2009. Statistical evaluation of triacylglycerol composition in plant oils based on high-performance liquid chromatography-atmospheric pressure chemical ionization mass spectrometry data. J. Agr. Food Chem. 57, 6888-6898.

Niyas, Z., Variyar, P.S., Gholap, A.S., Sharma, A., 2003. Effect of $\gamma$-irradiation on the lipid profile of nutmeg (Myristica fragrans Houtt.). J. Agr. Food Chem. 51, 6502-6504.

Pinto, P., Cabo Verde, S., Trigo, M.J., Santana, A., Botelho, M.L., 2007. Food irradiation: microbial, nutritional, and functional assessment. Radionuc. Concent. Food Environ. $164,411-438$.

Portuguese Government Legislation, 1994: Decreto Normativo 44/94, from February 3rd. Ministério da Agricultura, Desenvolvimento Rural e Pescas. Avaliable from : http://dre.pt/util/getpdf.asp?s=img\&serie=2\&iddr=28.1994\&data=1994-0203\&num=2S028A0000S00. 
Rombaut, R., De Clercq, N., Foubert, I., Dewettinck, K., 2009. Triacylglycerol analysis of fats and oils by evaporative light scattering detection. J. Am. Oil Chem. Soc. 86, 19-25. Shao, X. L., Li, Y.F., 2012. Classification and prediction by LF NMR. Food Bioprocess Tech. $5,1817-1823$.

Supriya, P., Sridhar, K.R., Nareshkumar S., Ganesh, S., 2012. Impact of electron beam irradiation on fatty acid profile of canavalia seeds. Food Bioprocess Tech. 5, 10491060.

UNEP, Montreal Protocol on substances that deplete the ozone layer, 2006. Report of the methyl bromide technical options committee, 205-206, 310-313.

Upchurch, B.L., Affeldt, H.A., Aneshansley, D.J., Birth, G.S., Cavalieri, R.P., Chen, P., Miller, W.M., Sarig, Y., Schmilovitch, Z., Throop, J.A., Tollner, E.W., 1993. Detection of internal disorders, Proc. of the Inter. Workshop United States-Israel Binational Agricultural Research and Development Fund. American Society of Agricultural Engineers, Sponkane, Washington 5, 80-85.

Zeb, A., 2012. Triacylglycerols composition, oxidation and oxidation compounds in camellia oil using liquid chromatography-mass spectrometry. Chem. Phys. Lipids 165, 608-614.

Zhang, Q., Ahmed S. M.S., Shen Q., 2012. Discrimination of edible vegetable oil adulteration with used frying oil by low field nuclear magnetic resonance. Food Bioprocess Tech. DOI: $10.1007 / \mathrm{s} 11947-012-0826-5$. 